\title{
The IFF: The Isopycnal Float Fluorometer
}

\author{
GARY L. HITCHCOCK \\ Nova University Oceanographic Center, Dania, Florida \\ E. J. LESSARD \\ Horn Point Environmental Laboratory, University of Maryland, Cambridge, Maryland \\ D. DORSON* \\ BathySystems, West Kingston, Rhode Island \\ J. FONTAINE AND T. ROSSBY \\ Graduate School of Oceanography, University of Rhode Island, Narrangansett, Rhode Island
}

(Manuscript received 3 March 1988, in final form 9 March 1988)

\begin{abstract}
An isopycnal float has been developed which provides a description of water parcel motion and simultaneous measurements of chlorophyll $a$ fluorescence, pressure and temperature along a chosen isopycnal surface. The device consists of a modified Swallow float with a "compressee" to match the compressibility of the float to that of seawater, so that pressure-induced buoyancy changes are removed. The solid-state fluorometer, modified from a preexisting design, provides a measure of the temporal variability in chlorophyll $a$ fluorescence. A pilot deployment of the float was made in September 1986 within a shelf water entrainment feature along the northern edge of the Gulf Stream near $37^{\circ} \mathrm{N}, 73^{\circ} \mathrm{W}$. A primary application of the float is to measure upwelling velocities and the concurrent changes in the chlorophyll $a$ fluorescence field.
\end{abstract}

\section{Introduction}

Within the past two decades the study of spatial distributions of oceanic phytoplankton have increasingly relied on the ability to determine chlorophyll $a$ distributions from continuous fluorescence measurements (e.g., Lorenzen 1966). Although pigment fluorescence per se does not provide a measure of phytoplankton biomass (Cullen 1982), the ability to continuously record chlorophyll $a$ fluorescence distributions from shipboard transects and from towed or moored submersible fluorometers has provided oceanographers with observations necessary to relate the vertical-horizontal distribution of phytoplankton to physical processes (Yentsch and Yentsch 1983). Along-track fluorescence profiles have shown, for example, that the distribution of chlorophyll plus phaeopigment $a(\mathrm{Chl}$ a) fluorescence at spatial scales of $0.1-10 \mathrm{~km}$ is pri-

\footnotetext{
* Also affiliated with the Graduate School of Oceanography, University of Rhode Island, Narrangansett, Rhode Island.
}

Corresponding author address: Dr. Gary Hitchcock, Nova University, Oceanographic Center, 8000 North Ocean Drive, Dania, FL 33004 . marily controlled by physical processes, rather than biological factors (Denman et al. 1977).

One common characteristic of the shipboard or towed fluorometers is that fluorescence is sampled in an Eulerian reference frame. These measurements are preferable if the spatial statistical properties of the water column are to be studied. Moored fluorometers have provided information on the temporal variability of Chl $a$ fluorescence in relation to physical properties (Whitledge and Wirick 1983). Fluorescence determined from a sampling platform providing a Lagrangian description of flow would, in contrast, provide the temporal history of a fluid parcel of interest. The development of the isopycnal Swallow float (ISF) offers oceanographers the capability to 'track' water parcel motion in a Lagrangian sense within strongly baroclinic regions (Rossby et al. 1985). Although these floats have been primarily used at intermediate depths in the Gulf Stream (Levine et al. 1986), the instruments offer biological oceanographers the capability to follow biological or chemical processes in relation to the horizontal and vertical motions of a tagged water parcel.

We have developed an isopycnal float which contains a solid state fluorometer for measurements of $\mathrm{Chl} a$ fluorescence, a thermistor and a pressure transducer. A brief overview of the principles of operation and a 


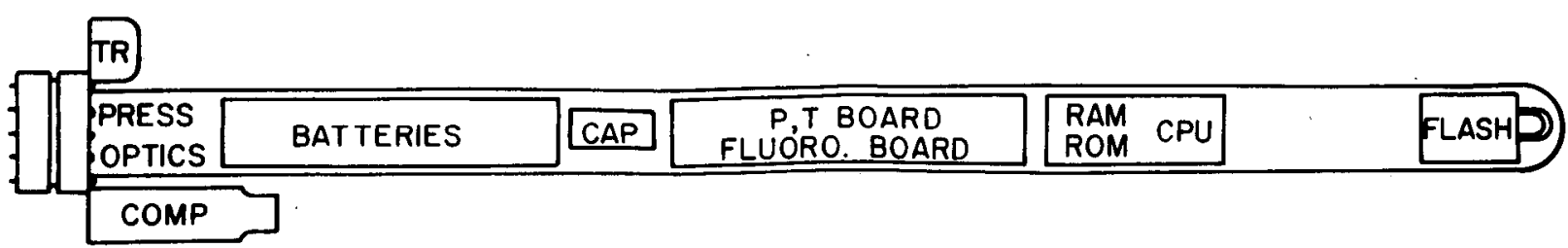

FIG. 1. Schematic diagram of the internal configuration of the isopycnal float fluorometer. The pressure transducer and fluorometer optics section are mounted on the aluminum endplate, with circuit boards mounted on a PVC rib. Separate battery packs are provided for the fluorometer excitation HV source and remaining circuitry. The pinger capacitor (CAP) is separate from the fluorometer and pressure, temperature circuit boards. The RAM, ROM and CPU is contained on one board. The xenon flasher, at the top of the float, rides ca. 30 $\mathrm{cm}$ above the water when the device floats on the surface.

description of the instrument is presented with observations from a test deployment in the Gulf Stream front. The instruments have also been successfully deloyed in a seasonal study of the Somali Current during the northeast and southwest monsoon seasons (Hitchcock, Frazel and Olson 1987).

\section{Theory of operation}

A complete description of float operation in both the isopycnal and isobaric modes is presented in Rossby et al. (1985). A standard Swallow float operates in a near-isobaric mode because its compressibility is much less than seawater, typically $50 \%$ less. As a result, when the float is displaced from an equilibrium pressure surface (such as an increase in depth) it gains buoyancy, and the restoring forces act to return it to an equilibrium pressure surface. In order to make a Swallow float approximate a Lagrangian follower of water parcel

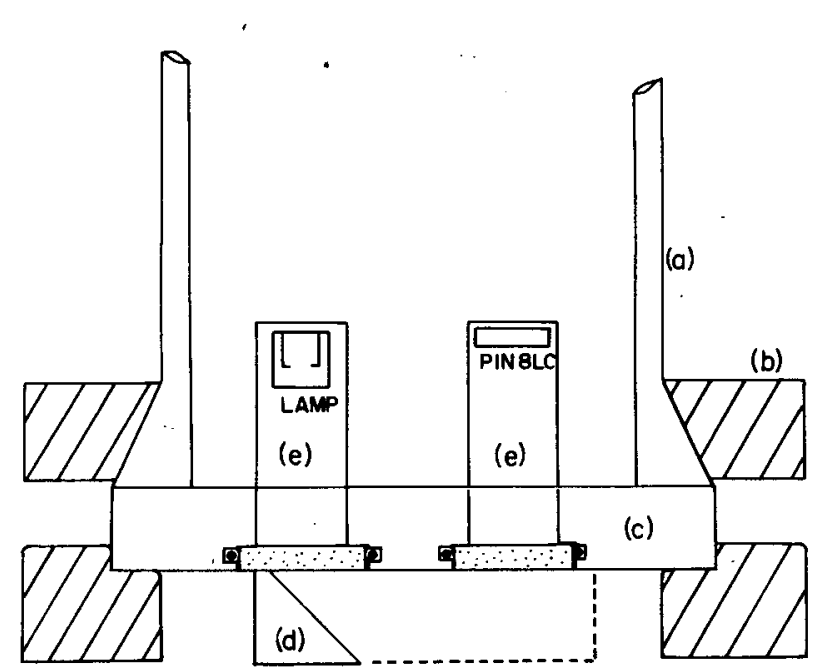

FIG. 2. Schematic diagram of the endplate assembly and fluorometer optics. The glass tube (a) is held by a delrin collar (b) to the aluminum endplate (c). The optics ports (stippled) are of optical glass. A planar mirror and light shroud (d) cover the light path. The filters and lenses (e) are positioned above the endplate and below the flashlamp and photodiode., motion in the vertical it is necessary to remove this pressure-induced buoyancy.

This is done by adding a compressee, a spring-backed piston within a cylinder. The compressee expands and contracts the float volume in response to changes in the hydrostatic pressure so that ideally the float has the same compressibility as seawater. The forces acting upon a neutrally buoyant float have been evaluated for representative salinity and temperature gradients in the North Atlantic, specifically for Gulf Stream waters by Rossby et al. (1985, Table 1). They conclude that glass, rather than metal, is preferable for float construction since glass has a much smaller coefficient of thermal expansion than seawater. In practice the floats have had compressibilities $80-90 \%$ that of seawater, although future designs will have a compressibility more closely matched to that of seawater.

The vertical deviation of a neutrally buoyant float from a designated isopycnal surface has been examined by Voorhis (1971) in which the response of the float was modeled as a forced, damped harmonic oscillator. Goodman and Levine (1986) have extended this study to determine the temporal response of floats to random forcings such as internal waves. The results indicate that these floats should closely track the designated isopycnal surface at temporal scales longer than the local buoyancy period.

\section{Mechanical description}

The isopycnal float fluorometer (IFF) is packaged in a glass tube similar in construction to isopycnal Swallow floats (Fig. 1). The glass tube is $1.64 \mathrm{~m}$ in length with an i.d. of $10.2 \mathrm{~cm}$ and $0.64 \mathrm{~cm}$ wall thickness. The float package has a volume of ca. $1.5 \times 10^{4}$ $\mathrm{cm}^{3}$ and weighs ca. $18 \mathrm{~kg}$ in air. The base of the tube is flared and sealed with a Teflon gasket to a $13.7 \mathrm{~cm}$ diameter aluminum endplate (Fig. 2 ). The endplate is secured by a two-piece delrin clamp. Rossby and Dorson (1983) have described the endplate assembly and mechanical design considerations for similar glass floats. The endplate contains a Swagelok lead-through for the pressure transducer and Mecca connectors for 


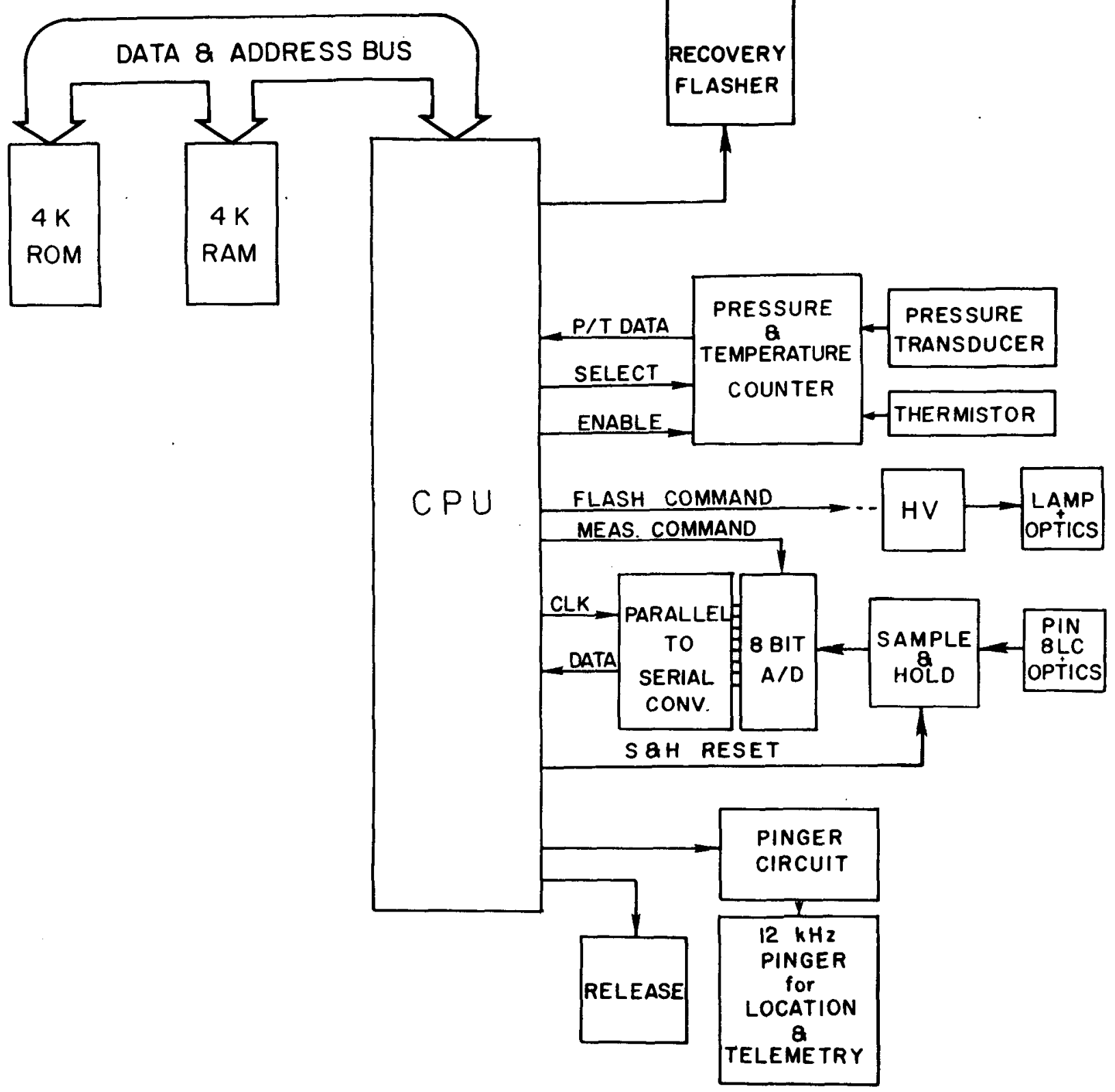

FIG. 3. Block diagram of the float electronics. The flash command for the fluorometer excitation command is optically isolated from the remaining circuitry. Sampling intervals and fluorometer excitation-fluorescence measurement timing are controlled by software. The release is actuated at the end of a deployment with a ballast weight dropped from a burn wire.

an acoustic transducer, ballast release wire and leads for monitoring the battery voltage.

The light paths for excitation and fluorescence are constructed of $2.54 \mathrm{~cm}$-diameter $\times 0.64 \mathrm{~cm}$-thick optical glass ports sealed with A-022 o-rings (Fig. 2). The ports have been successfully pressure tested to $600 \mathrm{db}$. The volume of water illuminated for excitation is approximately $1 \mathrm{~cm}^{3}$. A xenon flashlamp (E.G.\&G. FX108 lamp and FY-505 Lite-Pac) with a BG-18 Schott filter and lens, comprises the excitation source with a planar mirror and shroud mounted beneath the optics port. The photodetector assembly consists of a United Detector Technology PIN 8LC photodiode mounted above a RG 665 Schott filter and lens assembly.

A $12 \mathrm{kHz}$ acoustic transducer is attached to a flange on the upper end of the delrin collar, with the compressee mounted on the opposite side of the float (Fig. 1). The pressure transducer (Data Instruments Model EAF) and fluorometer optics are mounted on the endplate. Two $15 \mathrm{~V}$ battery supplies are above the endplate, 


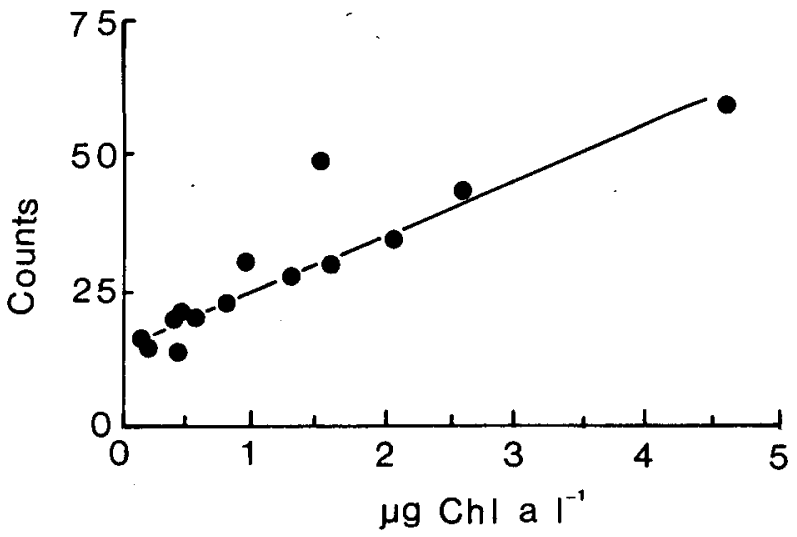

FIG. 4. Chl a fluorescence calibration of IFF No. 13. Samples for calibration include laboratory cultures of diatoms and chroococcoid cyanobacteria, plus natural populations from Narragansett Bay, Rhode Island.

one for the fluorometer HV supply and the other for electronics. The charging capacitor for the acoustic pinger voltage source is separate from other components. Separate circuit boards are provided for pressuretemperature measurements $(P, T$ board, Fig. 1$)$ and the fluorometer (fluoro. board, Fig. 1).

A xenon flashlamp at the top of the float (Fig. 1) is actuated at the end of a deployment for locating the float on the surface. The final step in ballasting the float is to add an expendable drop weight, which is jettisoned after a predetermined time that can be set at launch to either 24 or $48 \mathrm{~h}$. The float is retrieved by using a boat hook to attach a line to a polypropylene bail which extends approximately $30 \mathrm{~cm}$ above the glass tube.

\section{Electronics}

The operation of the float is controlled by a 6805 microprocessor with the deployment duration, sampling frequency and other aspects of the float operation stored in an assembly language program within ROM (Fig. 3). Temperature and pressure are sampled at 15 min intervals while a fluorescence count is stored every $30 \mathrm{~min}$. Temperature is measured by a thermistor with an accuracy of $0.1^{\circ} \mathrm{C}$; the thermistor is calibrated by means of an equivalent resistance box. The pressure transducer is calibrated by means of a dead weight tester. Conversion of the temperature and pressure signals to frequency is as described by Rossby and Dorson (1983). The fluorescence count stored in memory is the median of five individual measurements taken at $90 \mathrm{sec}$ intervals. Data collected over the preceeding 4 $\mathrm{h}$ is stored in RAM and transmitted to the ship via a $12 \mathrm{kHz}$ acoustic link at $15 \mathrm{~min}$ intervals. The acoustic output is recorded on a graphics recorder, as described for the ISF by Rossby et al. (1985), and is converted to temperature and pressure and fluorescence values by calibration factors determined empirically for each float.

The fluorometer design is modified from Aiken (1981). The circuitry is revised to incorporate a stable HV power supply (Analog Modules model 562) for the excitation light source. The HV capacitor is isolated from remaining circuitry by opto-isolators, to minimize transient voltage spikes in the electronics. The delay time for sensing fluorescence is controlled by the CPU, eliminating the requirement for a second photodiode and ratio detector as in the original design (Aiken 1981). In the current configuration, voltage from the photodiode is measured with a sample-and-hold circuit, converted to 8 bits by an A/D circuit after a specified delay time. The measured value is sent to the CPU in a serial fashion. The data is then stored in RAM. The fluorometer has been calibrated from 0.10 to approximately $10 \mu \mathrm{g} 1^{-1}$ total (chlorophyll plus phaeopigment) $\mathrm{Chl} a$ by recording fluorescence output as a function of (extracted) pigment concentrations while the float was immersed in seawater from Narragansett Bay, the Gulf Stream, or cultures of Synechococcus sp. and Skeletonema costatum. Data for $\mathrm{Chl}$ a concentrations ranging from 0.1 to $3 \mu \mathrm{g} \mathrm{L}^{-1}$ are presented in Fig. 4.

We have found that one of the most troublesome aspects of the original fluorometer design is its sensitivity to extraneous light and flash-to-flash variability. This was evident in the scatter of data relating fluorometer output to Chl $a$ concentration. We had initially proposed that by optimizing the delay of sampling time and incorporating shielding along the light path it would be possible to minimize this source of interference. One of us (G.H.) is currently evaluating alter-

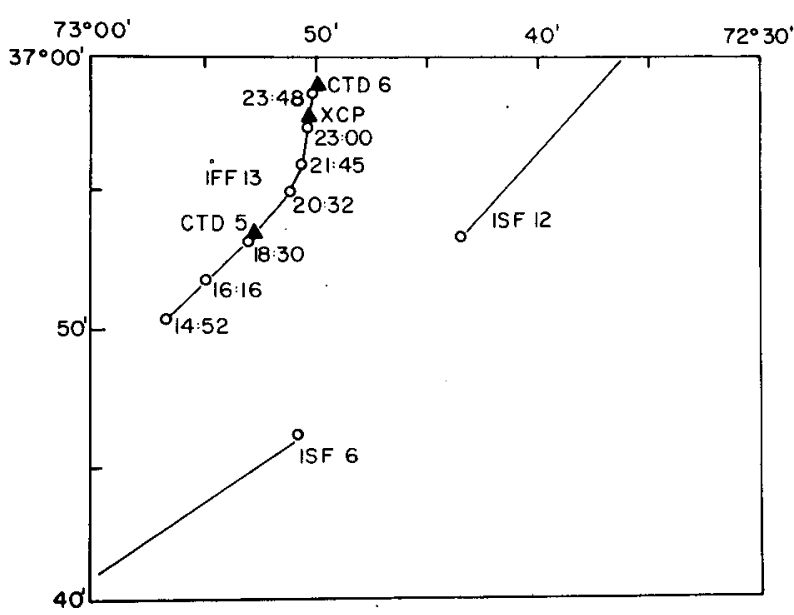

FIG. 5. Float trajectory for IFF 13 along the northern boundary of a shelf water entrainment feature. Open symbols indicate position and corresponding time (UTC) of overhead positions, with closed symbols positions of CTD and XCP drops. Paths of ISF floats within the feature (ISF 6, ISF 12) are shown for comparison. 


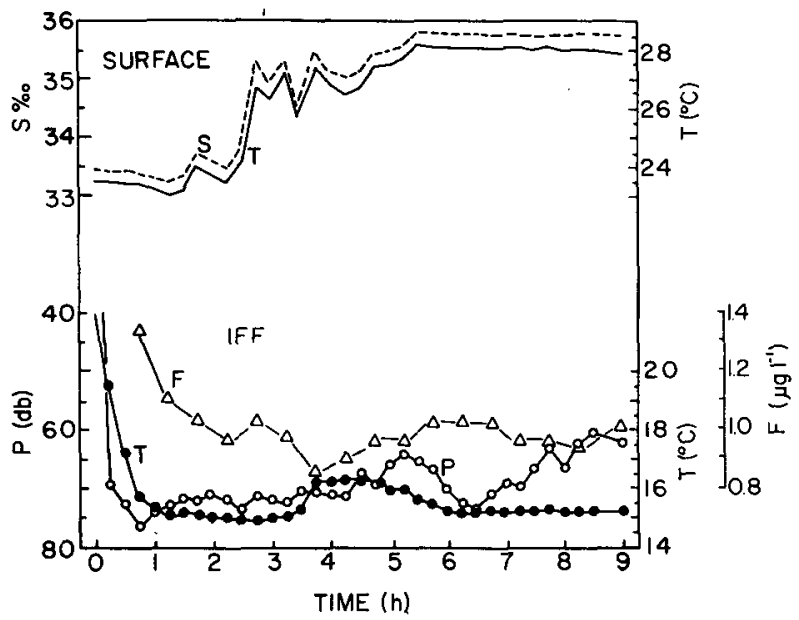

FIG. 6. Surface temperature $(T)$ and salinity $(S)$ from the ship's SAIL system (upper panel) and IFF 13 pressure $(P)$, temperature $(T)$ and fluorescence values $(F)$ (lower panel) during IFF 13 deployment. Fluorescence values extrapolated to Chl $a$ (chlorophyll plus phaeopigment) with calibration factors from Fig. 4.

native circuitry and mechanical aspects of the design to reduce this problem.

\section{Field deployment}

An initial field test of the IFF was scheduled in fall of 1985 aboard the R/V Hakon Mosby. However, mechanical difficulties with the ship's graphics recorder system prevented us from deploying the IFF. Subsequently, the first launch was made from the R/V Endeavor on 8 September 1986, within a shelf water entrainment feature along the edge of the Gulf Stream northeast of Cape Hatteras. More than $90 \mathrm{~h}$ of isopycnal Swallow float (ISF) and IFF deployments were made in this shelf water feature during the 7-day cruise. Although the physical aspects of shelf water entrainment has been described (Kupferman and Garfield 1977), there have been only limited attempts to describe the biological aspects of these features (Hitchcock et al., submitted). The results from the R/V Endeavor cruise will be reported separately (Levine et al., in preparation ); here we describe the relevant observations with the IFF to demonstrate its use in strong, near-surface baroclinic gradients.

The IFF was launched at $36^{\circ} 50.5^{\prime} \mathrm{N}, 72^{\circ} 56.9^{\prime} \mathrm{W}$ at 1450 UTC at the northern edge of the entrainment feature. The float reached an equilibrium at approximately $26.1 \sigma_{t}$, near the base of the entrainment feature. The initial path of the float was to the northeast at 67 $\mathrm{cm} \mathrm{s}^{-1}$, parallel to the path of ISFs within the center of the feature (Fig. 5). Surface temperature $\left(23.5^{\circ} \mathrm{C}\right)$ and salinity (33.5\% ) records from the SAIL system of the R/V Endeavor showed the surface waters had characteristic shelf water properties (Fig. 6). Between 1800 and 1845 UTC, the temperature of surface waters over the float increased from 23.5 to $>27^{\circ} \mathrm{C}$ as salinity increased from ca. 33.5\% to $35.5 \%$ (Fig. 6). These latter $T-S$ properties were characteristic of slope waters previously found north of the shelf water entrainment feature.

A CTD cast at 1830 UTC (CTD 5), made while the ship was positioned over the float, indicated there was considerable variability in the vertical distribution of temperature and salinity within the upper $125 \mathrm{~m}$ (Fig. 7 ). The surface salinity at CTD 5 was $>35.2 \%$, about $2 \% 0$ greater than that in the 'core' of the shelf water feature. Waters with salinity and temperature characteristics of shelf water were only evident at depth, near

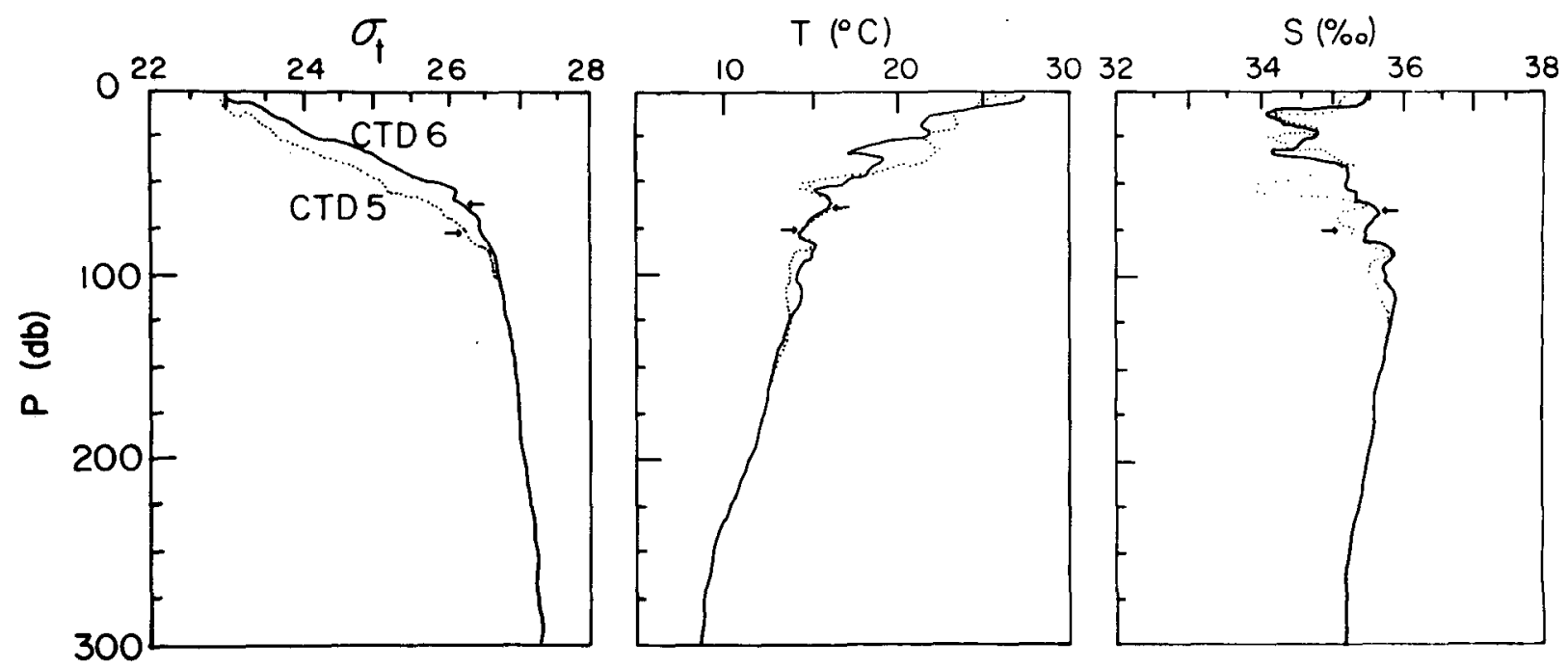

FIG. 7. Vertical profiles of density ( $\operatorname{sigma} t$ ) temperature and salinity at CTD 5 and 6 . Arrows indicate the pressure record of IFF 13 at time closest to the CTD casts. Note that variability in the $T-S$ structure is primarily confined to upper $150 \mathrm{~m}$. 
the $50 \mathrm{~m}$ isobath (Fig. 7). The corresponding pressure record from the float $(72 \mathrm{~m})$ placed it at the base of the pycnocline, in waters with a lower temperature $\left(14.8^{\circ} \mathrm{C}\right)$ and higher salinity $(35.1 \%)$ than at the surface. In general, the vertical distribution of temperature and salinity in the entrainment feature was quite erratic, with temperatures ranging over $5^{\circ} \mathrm{C}$ within 15 $\mathrm{m}$. Salinity was also variable, increasing from $33.9 \%$ at $55 \mathrm{~m}$ to $35.1 \%$ at $70 \mathrm{~m}$ (Fig. 7). Thus, the float appears to have equilibrated within the pycnocline where there was a high degree of stirring of near-surface shelf water and surrounding slope waters. Once the float had equilibrated, the Chl $a$ fluorescence records varied from 0.85 to $1.0 \mu \mathrm{g} \mathrm{l}^{-1}$, within the range of pigment concentrations from discrete samples (analyzed by fluorescence of $90 \%$ acetone extracts; Parsons et al. 1984) taken from Niskin bottles at the time of deployment (Table 1). The float was also located within the nitrate nutricline (method of Parson et al. 1984; Table 1), where subsurface pigment maxima are often observed (Cullen 1982).

Between 1845 and 2100 UTC, the float trajectory veered from the northeast to the north (Fig. 5) and the float began to oscillate vertically over a $10 \mathrm{db}$ interval with a period of approximately $2 \mathrm{~h}$. Temperature also increased from $15^{\circ}$ to $16^{\circ} \mathrm{C}$ as the float track turned to the north, then temperature subsequently decreased to the original 'equilibrium' value of $15^{\circ} \mathrm{C}$ during the last $3 \mathrm{~h}$ of deployment. The $\mathrm{Chl} a$ fluorescence values showed less variation, ranging from 0.9 to slightly $>1.0$ $\mu \mathrm{g} 1^{-1}$ during the final $5 \mathrm{~h}$ of deployment.

During the final $2 \mathrm{~h}$ of deployment, the float trajectory continued north at an average velocity of $79 \mathrm{~cm}$ $\mathrm{s}^{-1}$. The IFF surfaced at the predetermined time and was retrieved at $36^{\circ} 58.4^{\prime} \mathrm{N}, 72^{\circ} 49.8^{\prime} \mathrm{W}$ at $0020 \mathrm{UTC}$ 9 September. The depth of the float during the last 30 min of deployment was ca $60 \mathrm{~m}$, approximately $10 \mathrm{~m}$

TABLE 1. Temperature, salinity, nitrate, total pigment (chlorophyll and phaeopigment $a$ ) as a function of depth at CTD 5. Pressure, temperature and salinity from Sea Bird CTD system; nitrate and pigment data are from discrete samples collected by Niskin bottles. The samples were collected while the ship was located within $20 \mathrm{~m}$ of the float (in the horizontal); the float was at 70 to $75 \mathrm{db}$ during the CTD-hydrocast.

\begin{tabular}{rcccc}
\hline $\begin{array}{c}\text { Pressure } \\
(\mathrm{db})\end{array}$ & $\begin{array}{c}\text { Salinity } \\
(\% 0)\end{array}$ & $\begin{array}{c}\text { Temperature } \\
\left({ }^{\circ} \mathrm{C}\right)\end{array}$ & $\begin{array}{c}\text { Nitrate } \\
\left(\mu \mathrm{M} \mathrm{1}^{-1}\right)\end{array}$ & $\begin{array}{c}\text { Total Chl } a \\
\left(\mu \mathrm{g} \mathrm{I}^{-1}\right)\end{array}$ \\
\hline 6 & 35.165 & 26.55 & $\mathrm{ND}$ & 0.92 \\
16 & 34.385 & 23.25 & $\mathrm{ND}$ & 1.13 \\
26 & 34.313 & 21.52 & $\mathrm{ND}$ & 1.07 \\
36 & 35.058 & 22.19 & $\mathrm{ND}$ & 0.81 \\
46 & 34.869 & 19.29 & $\mathrm{ND}$ & 0.59 \\
56 & 33.929 & 14.88 & $\mathrm{ND}$ & 0.74 \\
66 & 35.502 & 16.20 & $\mathrm{ND}$ & 1.07 \\
76 & 35.375 & 14.94 & 3.22 & 0.75 \\
86 & 35.711 & 15.04 & 5.14 & 0.56 \\
96 & 35.562 & 13.86 & 6.79 & 0.35 \\
106 & 35.665 & 13.90 & 8.50 & 0.27 \\
\hline
\end{tabular}

less than when the float was within the shelf water entrainment feature. A CTD cast (CTD 6) taken within $30 \mathrm{~min}$ of retrieval showed the float was still associated with the $26.1 \sigma_{t}$ surface. The temperature $\left(15.5^{\circ} \mathrm{C}\right)$ and salinity $(35.4 \% 0)$ of this isopycnal surface was greater than that found at CTD 5.

\section{Summary}

The IFF has been developed to provide biological oceanographers with the capability to determine water parcel motion in the $x, y$ and $z$ axes and simultaneously monitor Chl $a$ fluorescence on designated isopycnal surfaces. The isopycnal properties of the float permit us to determine upwelling and downwelling velocities as well as the temporal change in $\mathrm{Chl} a$ fluorescence. The floats will be useful for examining these physical processes and $\mathrm{Chl} a$ distributions with spatial scales on the order of hundreds to thousands of meters in the horizontal and meters in the vertical. The temporal scales of the physical processes of interest area on the order of hours to days.

The Lagrangian characteristics of the floats offer an alternative to moored current meters and fluorometers (Weller et al. 1985; Whitledge and Wirick 1983) in examining the relationship between horizontal-vertical velocities and pigment distributions. When deployed in groups, the IFF offers the potential for examining the variability and mean in the horizontal subsurface $\mathrm{Chl} a$ field in relation to divergence or convergence.

We are currently modifying the IFF design into a prototype float for long-term deployments with remote relay of acquired data via the Argos satellite, as in the RAFOS system (Rossby et al. 1986). This effort includes the development of fluorometer circuits to improve both resolution and sensitivity. The floats are to be deployed for periods of days to weeks, and should complement surface pigment distributions derived from remote sensing. These instruments will record the pigment distributions and Lagrangian paths associated with physical processes having longer spatial and temporal scales than now feasible with the shiptracked IFF.

Acknowledgments. We wish to thank Drs. E. Levine and $\mathrm{D}$. Conners for their assistance in the technical development of the IFF, and for providing the opportunity for a field trial during cruise En-147 of the R/ V Endeavor through ONR 422PO. Mr. D. Butler assisted in the development of the instrument and operated the U.R.I. pressure tank facility. This work has been funded by the Office of Naval Research under Contracts N00014-81-C-0062, N00014-87-K-0040 and NSF Grant OCE 85-04148.

\section{REFERENCES}

Aiken, J., 1981: A chlorophyll sensor for automatic, remote operation in the marine environment. Mar. Ecol. Prog. Ser., 4, 235-239. 
Cullen, J. J., 1982: The deep chlorophyll maximum: Comparing vertical profiles of chlorophyll a. Can. J. Fish. Aquat. Sci., 39, 791803.

Denman, K., A. Okubo and T. Platt, 1977: The chlorophyll fluctuation spectrum in the sea. Limnol. Oceanogr., 22, 1033-1038.

Goodman, L., and E. R. Levine, 1986: Response characteristics of isopycnal floats. EOS, 67(44), 1023.

Hitchcock, G. L., D. W. Frazel and D. B. Olson, 1987: The use of an isopycnal float-fluorometer during a seasonal study of the Somali Current. EOS, 68, 1744.

- D. V. Holliday, R. E. Pieper and D. W. Frazel: Plankton biomass in relation to shelf water entrainment features along the Gulf Stream front. Biol. Oceanogr., submitted.

Kupferman, S. L., and N. Garfield, 1977: Transport of low-salinity water at the slope water-Gulf Stream boundary. J. Geophys. Res., 82(C6), 3481-3486.

Levine, E. R., D. N. Connors, P. C. Cornillion and H. T. Rossby, 1986: Gulf Stream kinematics along an isopycnal float trajectory. J. Phys. Oceanogr., 16, 1317-1328.

Lorenzen, C. J., 1966: A method for the continuous measurement of in vivo chlorophyll concentration. Deep-Sea Res., 13, 223 227.
Parsons, T. R., Y. Maita and C. M. Lalli, 1984: A Manual of Chemical and Biological Methods for Seawater Analysis. Pergamon Press. $173 \mathrm{pp}$.

Rossby, H. T., and D. Dorson, 1983: The deep-drifter-A simple tool to determine average ocean currents. Deep-Sea Res., 30, 1279-1288.

- E. R. Levine and D. N. Connors, 1985: The isopycnal Swallow float-A simple device for tracking water parcels in the ocean. Prog. Oceanogr., 14, 511-525.

- D. Dorson and J. Fontaine, 1986: The RAFOS system. J. Atmos. Oceanic Technol., 3, 672-679.

Voorhis, A. D., 1971: Response characteristics of the neutrally buoyant float. WHOI Ref. No. 71-73, 56 pp.

Weller, R. A., J. P. Dean, J. Marra, J. F. Price, E. A. Francis and D. C. Boardman, 1985: Three-dimensional flow in the upper ocean. Science, 227, 1552-1556.

Whitledge, T. E., and C. D. Wirick, 1983: Observations of chlorophyll concentrations off Long Island from a moored in situ fluorometer. Deep-Sea Res., 30(3A), 297-309.

Yentsch, C., and C. Yentsch, 1984: Emergence of optical instrumentation for measuring biological properties. Oceanogr. Mar. Biol. Ann. Rev., 22, 55-98. 